\title{
Substantiation of development system parame- ters taking into account the main dimensions of working equipment used in the development of mineral deposits by open-pit method
}

\author{
P.O. Tyukov, E.V. Loginov \\ Saint Petersburg Mining University, Saint Petersburg, Russia
}

\begin{abstract}
The text substantiates the dependence of the complex dimensions of and transportation equipment (excavator - dump truck links) on the parameters of the mining method, which ensures an increase in the efficiency of open-pit mining of mineral deposits, is justified in the text. Increasing the efficiency of open-pit mining method using a complex of extraction and loading and transportation equipment is achieved by increasing the range of permissible parameters of the mining method. The study allowed to identify

- the dimensions of the extraction and loading and transportation equipment complex (excavator - dump truck links) affect the height of the bench and the width of the working platform

- the dimensions of the mining and loading equipment (excavator - dump truck links) are the main indicators that affect the parameters of the mining method at the complex of mining and loading and transportation equipment.
\end{abstract}

\section{Introduction}

Currently, opencast mining is developing in the direction connected with using more advanced equipment which significantly bigger linear dimensions. This leads to an increase in the parameters of the mining method.

Of the main technological processes in the development of mineral deposits of the open type, we can distinguish two processes that have a greater influence on the mining method parameters: extraction and loading and transportation of rock mass [1-3].

The most popular extraction and loading equipment used in open pits is a mechanical shovel of excavator type. Analysis of the trend of using excavators in the development of opencast mineral deposits has shown an increase in the number of powerful quarry excavators with working equipment backhoe hydraulic excavators and rope excavator with a front shovel $[4,5]$.

Many scientists were engaged in the development of mining technologies based on using single-bucket excavators in combination with road vehicles (excavator - dump truck link) [6]. The researchers paid attention to issues that are connected with the principle of operation, the scope of working equipmentapplication , open-pit mining technology. How- 
ever, most of them did not take into account the impact of the dimensions of modern working equipment on the parameters of the mining method.

\section{Methods}

Open pit mining of mineral deposits is prevalent both in the global mining industry and in the Russian Federation. More than $70 \%$ of all solid minerals are mined in the Russian Federation are mined through open pits and coal mines, thus producing $100 \%$ of building materials, $70 \%$ of coal, $80-93 \%$ of ores of ferrous and nonferrous metals [7].

Currently, opencast mining is developing in the direction thatis associated with the use of a more advanced equipment that has significantly bigger dimensions, which leads to an increase in the parameters of the mining method.

\subsection{Determination of the altitude}

It is necessary to observe safety rules when determining the height of the bench. That is, developing the type of direct mechanical shovel excavators for operating in soft rocks, the height of the bench should be taken either equal or less than the height of the maximum digging of the excavator (to avoid the formation of so-called overhangs); for operation in rock formations, the height of the bench might be 1.5 times bigger but during use it (D\&B), it must not exceed the height of the rock fall. The height of the bench should be determined by the design, taking into account the repeated results of the study of physical and mechanical properties of rocks and mining and geological conditions of their occurrence, as well as the parameters of the equipment used. The formation of overhangs on the ledge is not allowed [8].

\subsection{The work area width determination}

The design dimensions of the benches are design values, averaged over the length of the mining front; and to a certain extent, they depend on the rate of bench and the available mass of rock to be mined. In reality, the bench width along the mining front varies around average values due to inconsistencies in production processes [9].

In the study, methods for determining the bench width were classified (Figure. 1):

1. Calculation method for hard rock mined by drilling and blasting (the main parameter is $B_{x}$-width of the shot pile after one blast)

2. Calculation method for unconsolidated, soft rock mined without preliminary fragmentation (the main parameter is the benching width A). 


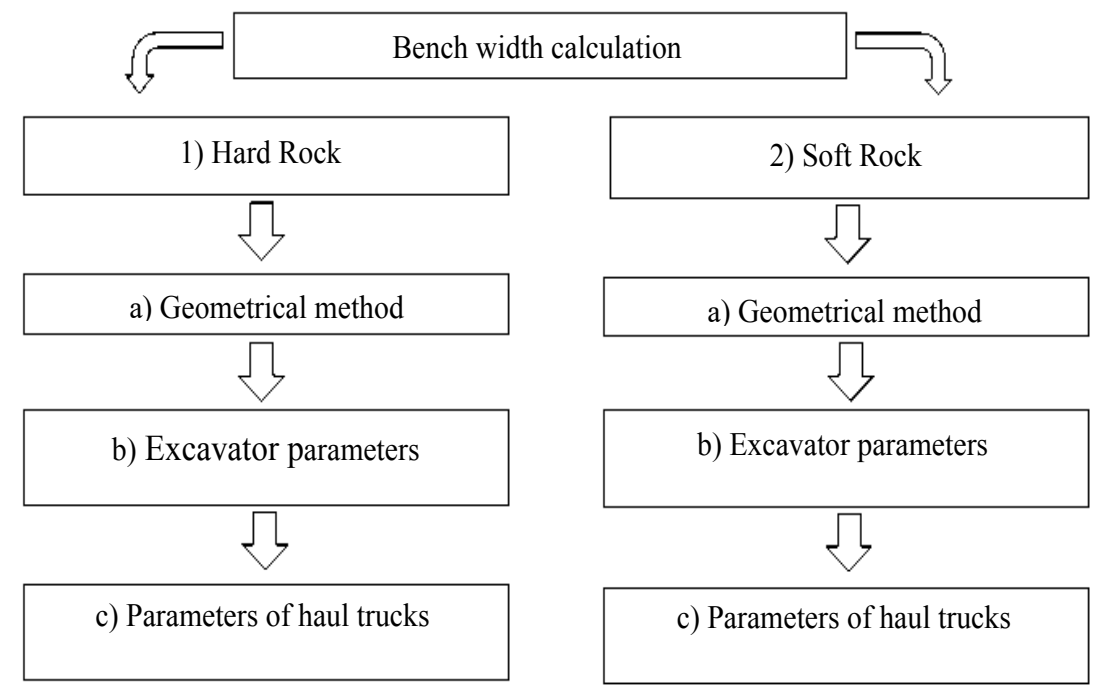

Fig. 1. Classification of methods to determine the workbench width: a - the geometrical method (the main parameter is the pit wall angle $(\varphi)$ ); $b$ the method based on the parameters of mining and loading equipment (the main parameter is specifications of a single-bucket excavator); $\mathrm{c}$ - the method based on the parameters of transportation equipment (the main parameters are specifications of haul trucks).

During the study, an analysis of existing methods of determining the width of the working platform was conducted and the two main methods for soft and hard rocks were identified, the calculation was performed using the existing methods, the results are shown in Tables 1 and 2 .

Table 1. The main study results for hard rocks G.P.

\begin{tabular}{|c|c|c|c|c|c|}
\hline $\begin{array}{l}\text { Excava- } \\
\text { tor } \\
\end{array}$ & Haul trucks & $\begin{array}{l}\mathrm{h}^{*}, \\
\mathrm{~m}\end{array}$ & $\begin{array}{l}\text { Shot pile width of after one } \\
\text { blast, } m\end{array}$ & $\begin{array}{l}\text { Bench } \\
\text { width, } \mathrm{m}\end{array}$ & $\begin{array}{l}\text { Bench } \\
\text { width**, m }\end{array}$ \\
\hline \multirow{3}{*}{ EKG -8 } & Belaz -7555 & \multirow{3}{*}{12.5} & \multirow{3}{*}{48.5} & \multirow{3}{*}{64.9} & 24.7 \\
\hline & Cat 773E & & & & 26.7 \\
\hline & $\begin{array}{l}\text { Komatsu } \\
\text { HD465-7R }\end{array}$ & & & & 24.4 \\
\hline \multirow{3}{*}{$\begin{array}{l}\text { EKG - } \\
10\end{array}$} & Belaz -7558 & \multirow{3}{*}{13.5} & \multirow{3}{*}{50.4} & \multirow{3}{*}{68.4} & 27.9 \\
\hline & Cat $775 \mathrm{G}$ & & & & 28.3 \\
\hline & $\begin{array}{l}\text { Komatsu } \\
\text { HD785-7 }\end{array}$ & & & & 26.9 \\
\hline \multirow{3}{*}{$\begin{array}{l}\text { EKG - } \\
12\end{array}$} & Belaz -7513 & \multirow{3}{*}{15} & \multirow{3}{*}{53.1} & \multirow{3}{*}{71.1} & 31.2 \\
\hline & Cat $777 \mathrm{G}$ & & & & 29.4 \\
\hline & $\begin{array}{l}\text { Komatsu } \\
\text { HD1500-5 }\end{array}$ & & & & 30.9 \\
\hline \multirow{3}{*}{$\begin{array}{l}\text { EKG - } \\
15\end{array}$} & Belaz -7518 & \multirow{3}{*}{16.4} & \multirow{3}{*}{55.5} & \multirow{3}{*}{73.9} & 33.8 \\
\hline & Cat 785D & & & & 33.5 \\
\hline & $\begin{array}{l}\text { Komatsu } \\
\text { HD730E }\end{array}$ & & & & 34.5 \\
\hline EKG - & Belaz -7530 & 17 & 56.5 & 76.5 & 35.2 \\
\hline
\end{tabular}




\begin{tabular}{|c|c|c|c|c|c|}
\hline \multirow[t]{3}{*}{20} & Cat 793D & & & & 36.2 \\
\hline & $\begin{array}{l}\text { Komatsu } \\
\text { HD830E }\end{array}$ & & & & 34.4 \\
\hline & Belaz -7532 & & & & 37.74 \\
\hline \multirow{3}{*}{$\begin{array}{l}\text { EKG - } \\
25\end{array}$} & Cat 793F & 18 & 58.1 & 78.1 & 37.2 \\
\hline & $\begin{array}{l}\text { Komatsu } \\
\text { HD860E }\end{array}$ & & & & 37.6 \\
\hline & Belaz -7560 & & & & 39.6 \\
\hline \multirow{3}{*}{$\begin{array}{l}\text { EKG - } \\
30\end{array}$} & Cat 795F AC & 18.5 & 58.9 & 79.9 & 41.5 \\
\hline & $\begin{array}{l}\text { Komatsu } \\
\text { HD930E-3 }\end{array}$ & & & & 36.8 \\
\hline & Belaz -7560 & & & & 39.5 \\
\hline \multirow{2}{*}{$\begin{array}{l}\text { EKG - } \\
35 \kappa\end{array}$} & Cat $795 \mathrm{~F} \mathrm{AC}$ & 18.3 & 58.6 & 79.6 & 41.4 \\
\hline & $\begin{array}{l}\text { Komatsu } \\
\text { HD960E }\end{array}$ & & & & 38.2 \\
\hline
\end{tabular}

*Bench height.

**Parameters of the haul trucks.

Table 2. The main study results for soft rocks G.P.

\begin{tabular}{|c|c|c|c|c|}
\hline Excavator & Haul trucks & $\mathrm{h}^{*}, \mathrm{~m}$ & Bench width, $\mathrm{m}$ & Bench width**, m \\
\hline \multirow{3}{*}{ EKG -8} & Belaz -7555 & & & 24.7 \\
\hline & Cat $773 \mathrm{E}$ & 12.5 & 36.1 & 26.7 \\
\hline & Komatsu HD465-7R & & & 24.4 \\
\hline \multirow{3}{*}{ EKG -10 } & Belaz -7558 & & & 27.9 \\
\hline & Cat $775 \mathrm{G}$ & 13.5 & 38.2 & 28.3 \\
\hline & Komatsu HD785-7 & & & 26.9 \\
\hline \multirow{3}{*}{ EKG -12 } & Belaz -7513 & & & 31.2 \\
\hline & Cat $777 \mathrm{G}$ & 15 & 40.9 & 29.4 \\
\hline & Komatsu HD1500-5 & & & 30.9 \\
\hline \multirow{3}{*}{ EKG - 15} & Belaz -7518 & & & 33.8 \\
\hline & Cat 785D & 16.4 & 43.5 & 33.5 \\
\hline & Komatsu HD730E & & & 34.5 \\
\hline \multirow{3}{*}{ EKG -20 } & Belaz -7530 & & & 35.2 \\
\hline & Cat 793D & 17 & 42.8 & 36.2 \\
\hline & Komatsu HD830E & & & 34.4 \\
\hline \multirow{3}{*}{ EKG -25 } & Belaz -7532 & & & 37.74 \\
\hline & Cat 793F & 18 & 44.4 & 37.2 \\
\hline & Komatsu HD860E & & & 37.6 \\
\hline EKG -30 & Belaz -7560 & 18.5 & 46.6 & 39.6 \\
\hline
\end{tabular}




\begin{tabular}{llll}
\hline & Cat 795F AC & 41.5 \\
& Komatsu HD930E-3 & & 36.8 \\
& Belaz -7560 & & 39.5 \\
EKG -35א & Cat 795F AC & 18.3 & 48.2 \\
& Komatsu HD960E & & 41.4 \\
& & & 38.2 \\
\hline
\end{tabular}

*Bench height.

**Parameters of the haul trucks.

\section{Conclusions}

The study has shown that

- The dimensions of the complex of excavation and loading-unloading and transport equipment complex (excavator - dump truck links) mostly affect the height of the bench and the width of the working platform.

- The main indicator influencing the parameters of the mining operation method when using extraction and loading and transportation equipment using (excavator - dump truck links) in a complex is the overall dimensions of extraction and loading equipment.

- The influence of the dependence of the complex of the overall dimensions of extraction and loading and transportation equipment (excavator - dump truck links) on the mining operation reveals the system parameters (Figures 2-3).

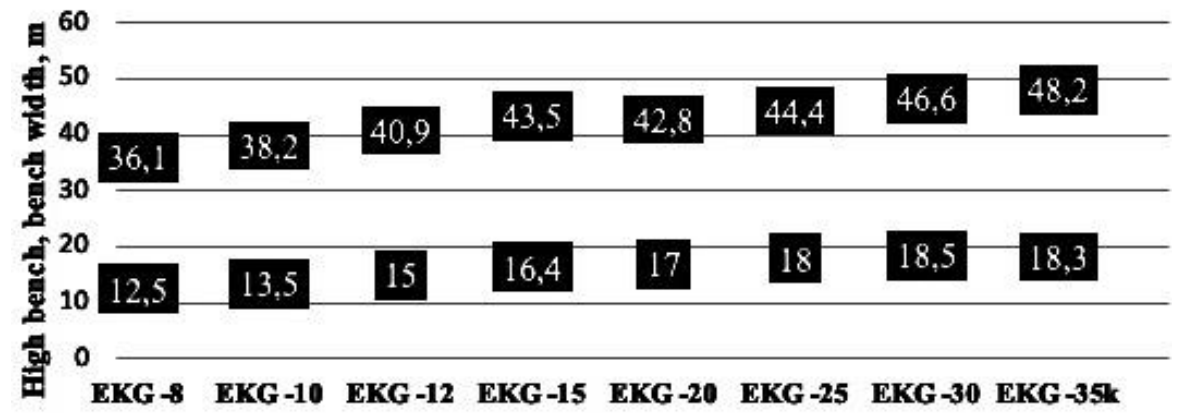

Fig. 2. Graph of the dimensions of extraction and loading equipment by the mining method parameters in the soft rock.

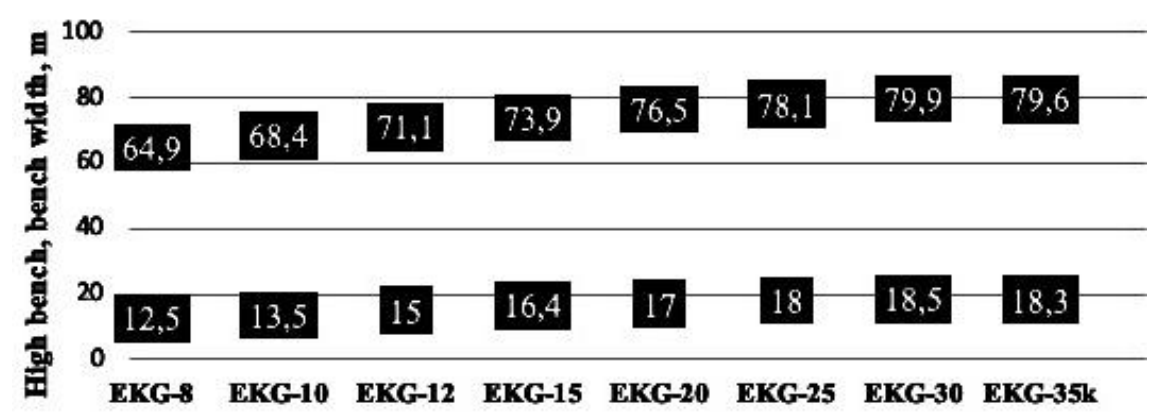

Fig. 3. Graph of the dimensions of extraction and loading equipment by the mining method parameters in the hard rock . 
Having analyzed the dependence graphs presented in Figures 2 and 3, we can conclude that this dependence is non-linear. The values of bench width are averaged over the length of the mining front, but cannot be less than the calculated minimum value. For effective work of the open pit, it is necessary to create conditions for uninterrupted operation of the excavator - dump truck links. Linear parameters of the excavator limit the main parameters of the mining method; in these conditions, the machines have a large area for maneuvering. If necessary, the width of the bench can be increased, but the overall dependence will not change and will have a consistent non-linear nature.

\section{References}

1. D. N. Ligotsky, K. V. Mironova Perspective Technology of Open-Pit Mining of Limestone and Dolomite. Journal of Engineering and Applied Sciences, 13, 1613-1616 (2018)

2. Argimbaev K.R. \& Kholodnjakov H.A. Erection methods and constructions of primary tailing dike. International Journal of Ecology and Development, 30(2), 47-54 (2015)

3. S. I. Fomin, V. V. Ivanov Improving the reliability of the opencast system for complex structure ore deposits. International Journal of Civil Engineering and Technology, 13(9), 36-43 (2018)

4. K. R. Argimbaev, D. N. Ligotsky, E. V. Loginov, K. V. Mironova Crack Formation Study in a Dam of a Formed Technogenic Deposit. Journal of Engineering and Applied Sciences, 14, 2258-2261 (2019)

5. S.I. Fomin Foundations for technical solutions in organizing excavation of open ore pits. Journal of mining institute, 221, 644-650 (2016)

6. E. V. Loginov, O. Y. Loktiukova, M. M. Melnitskaya Calculation of Bench Width for Backhoe Hydraulic Excavators Operated in Sinking Mining Systems. Journal of Engineering and Applied Science, 14(17), 6444-6448 (2019)

7. E. Loginov Improving the Efficient of Mining in the Deposit of Broken Stone. International University of Resources. Scientific Reports on Resource Issues, 1, 183-185 (2015)

8. K. Argimbaev, H. Kholodnjakov Determining the Safe Working Height of a Power Shovel for the Development of Iron-Bearing Tailing Dumps. World Applied Sciences Journal, 27(8), 1087-1090 (2013)

9. R. Thompson, A. Visser Selection and maintenance of mine haul road wearing course materials. Institute of Mining, Metallurgy, and Materials (IMMM), 115(4), 140-153 (2006) 